\title{
ANALISIS EFEKTIFITAS IMPLEMENTASI KEBIJAKAN PEMERINTAH DALAM KONTEKS KETERLIBATAN PEMANGKU KEPENTINGAN (STAKEHOLDER ENGAGEMENT): STUDI KASUS PROGRAM REVALUASI BARANG MILIK NEGARA PADA KEMENTERIAN KEUANGAN
}

\author{
Oleh: \\ Eko Prasetyo \\ Prodi Ilmu Administrasi Negara \\ Universitas Islam Syekh Yusuf Tangerang \\ prasetyo@unis.ac.id
}

\begin{abstract}
ABSTRAK
Pelaksanaan kebijakan pemerintah dalam program dan kegiatan seringkali terkendala oleh lemahnya koordinasi dan keterlibatan para pemangku kepentingan. Program Revaluasi Barang Milik Negara (BMN) yang dilakukan oleh Kementerian Keuangan menghadapi persoalan yang serupa sehingga proses Revaluasi BMN berjalan lambat dan membutuhkan waktu yang lama untuk melakukan validasi data. Penelitian ini bermaksud mengungkap penyebab dari kendala tersebut serta bagaimana meningkatkan keterlibatan pemangku kepentingan dalam program Revaluasi BMN, sehingga upaya untuk menyajikan nilai aset yang wajar di dalam neraca pemerintah dapat dicapai. Metode penelitian yang digunakan adalah penelitian kualitatif, dengan melakukan riset kepustakaan, studi literatur berdasarkan berbagai referensi, dokumen dan sumber yang terpercaya pada Direktorat Jenderal Kekayaan Negara Kementerian Keuangan. Penelitian ini menunjukkan bahwa implementasi kebijakan berupa Program Revaluasi BMN belum berjalan efektif dan keterlibatan pemangku kepentingan (stakeholder engagement) masih rendah. Hal tersebut disebabkan oleh rendahnya kemampuan SDM satuan kerja pada Kementerian/Lembaga, lemahnya kemampuan pengelolaan BMN oleh satuan kerja, dan rendahnya komitmen satuan kerja terhadap kesuksesan Program Revaluasi BMN. Untuk itu perlu dilakukan stakeholder mapping, serta memilih pendekatan yang berbeda untuk stakeholder yang berbeda.
\end{abstract}

Kata kunci: Pengelolaan Aset Negara, Revaluasi Barang Milik Negara, Keterlibatan Pemangku Kepentingan, Implementasi Kebijakan.

\section{ABSTRACT}

Policy implementation in the government programs and activities is often constrained by weak coordination of stakeholders. The State-Owned Property (SOP) Revaluation Program conducted by the Ministry of Finance in 2017 and 2018 runs slowly and takes a long time to validate the revaluation data. This study intends to uncover the causes of these constraints and how to increase stakeholder engagement in the SOP Revaluation Program. The research method used is qualitative research. The research will conduct literature studies based on various references, documents, and reliable sources at the Directorate General State Asset Management of the Ministry of Finance. This research shows that the policy implementation in the SOP Revaluation Program has not been effective. This shows the low-level of stakeholder engagement caused by the low capability of the human resources at the units of the Ministries/Institutions, the low quality of the SOP management by the units, and the low commitment of the units to achieve the objectives of the program. For this reason, stakeholder mapping needs to be done, as well as choosing a different approach for different stakeholders. 
Keywords: State Asset Management, State Owned Property Revaluation, Stakeholder Engagement, Policy Implementation

\section{A. PENDAHULUAN}

\section{Latar Belakang}

Pada tahun 2017 dan 2018, Kementerian Keuangan memiliki program besar yang berskala nasional yaitu Revaluasi Barang Milik Negara (BMN). Revaluasi BMN merupakan salah satu upaya untuk meningkatkan kredibilitas dan good governance pemerintah melalui pengungkapan nilai wajar atas aset di dalam Laporan Keuangan Pemerintah Pusat.

Revaluasi BMN tahun 2017 ini merupakan update dari inventarisasi dan penilaian yang dilakukan pada tahun 2010 dimana nilai BMN pada saat itu sebesar Rp1.244 triliun. Nilai wajar atas BMN yang dikelola akan memberikan peluang bagi Pemerintah untuk mendukung pembiayaan APBN melalui penerbitan Surat Berharga Syariah Negara (Sukuk). Selain itu, Revaluasi BMN akan menyajikan data terkini tentang kondisi BMN sehingga memberikan peluang utilisasi yang lebih optimal.

Direktur Jenderal Kekayaan Negara Isa Rachmatarwata pada acara pencanangan Revaluasi BMN tanggal 29 Agustus 2017, menyatakan bahwa kegiatan Revaluasi BMN dipersiapkan dan dilakukan bersama-sama Kementerian/Lembaga. Kegiatan Revaluasi BMN merupakan tindak lanjut arahan Menteri Keuangan atas hasil keputusan Rapat Kerja Komisi XI DPR RI dengan Menteri Keuangan pada 23 Mei 2016. Bahkan Dewan Perwakilan Rakyat (DPR) meminta agar Menteri Keuangan melakukan revaluasi terhadap BMN yang akan digunakan kembali (roll over) sebagai dasar penerbitan underlying asset SBSN (Kemenkeu, 2017).

Pelaksanaan program Revaluasi BMN selama tahun 2017 dan 2018 adalah dengan target melakukan penilaian kembali terhadap 934.409 item BMN yang berupa 108.524 bidang tanah, 434.801 item gedung dan bangunan serta 391.084 item jalan, irigasi dan jaringan yang diperoleh sampai dengan 31 Desember 2015 (Kemenkeu, 2017).

Sebelum Revaluasi BMN dimulai, pemerintah telah melakukan persiapan dengan kegiatan konsultansi ke Komite Standar Akuntansi Pemerintah/KSAP dan Badan Pemeriksa Keuangan/BPK mengenai standar dan objek penilaian kembali BMN, agar pelaksanaannya sesuai dengan ketentuan. Persiapan juga mencakup melakukan koordinasi dengan Kementerian/Lembaga, antara lain dengan Bimbingan dan Pelatihan Teknis bagi para petugas pada Kementerian/Lembaga yang akan terlibat langsung dengan pelaksanaan penilaian kembali BMN.

Namun demikian, dalam pelaksanaan Revaluasi BMN tersebut, terdapat kendala yang ditemui oleh Tim Pelaksana Revaluasi BMN yang terutama disebabkan oleh kurangnya keterlibatan dan kolaborasi antara Kemenkeu dengan Kementerian/Lembaga sehingga proses Revaluasi BMN berjalan lambat dan dibutuhkan waktu yang lama untuk melakukan validasi data hasil Revaluasi BMN. Penelitian ini bermaksud mengungkap penyebab dari kendala tersebut serta bagaimana meningkatkan keterlibatan pemangku kepentingan dalam program Revaluasi Barang Milik Negara sehingga tujuan dari revaluasi yaitu untuk menyajikan nilai asset yang wajar di dalam neraca pemerintah dapat dicapai.

\section{Konsep Efektivitas}


Efektivitas berkaitan dengan penilaian apakah sesuatu program telah memberikan pengaruh sesuai yang diharapkan, dimana efektivitas lebih menekankan kepada pencapaian dampak (impact) baik positif ataupun negatif dari suatu kebijakan publik terhadap kelompok atau pihak tertentu yang diinginkan. Efektivitas sebuah program dipengaruhi baik oleh evaluasi yang obyektif maupun yang subyektif yang didalamnya terdapat faktor politik, kurangnya keterampilan analisis, atau lemahnya proses evaluasi (Hugo, 2004). Penilaian terhadap efektivitas dari suatu organisasi adalah dilihat dari seberapa besar tingkat ketercapaian tujuannya (Lane, 1995). Pengukuran efektivitas dapat dilakukan dengan pendekatan sasaran, pendekatan sumber (system resource approach), pendekatan proses, ataupun pendekatan gabungan (intergratif) (Lubis dan Huseini, 2009).

\section{Konsep Implementasi Kebijakan}

Implementasi kebijakan merupakan aplikasi dari kebijakan pemerintah oleh para pelaksananya (mesin birokrasi). Implementasi kebijakan ditunjukkan oleh fase setelah ditetapkannya kebijakan dalam produk hukum perundangan yang selanjutnya dilaksanakan secara efektif. Kebijakan yang terimplementasi ditunjukkan oleh penerapan kebijakan pada target tertentu untuk mencapai tujuan yang diinginkan (Anderson, 2011). Hakekatnya, implementasi kebijakan merupakan tahapan di dalam proses kebijakan dimana tindakan untuk menyelesaikan permasalahan dilakukan. Pada tahap ini rancangan kebijakan telah berubah dan memberikan pengaruhnya, karena kebijakan telah dilaksanakan oleh badan-badan administrastif di pemerintahan (Theodoulou dan Kofinis, 2004).

\section{Keterlibatan Pemangku Kepentingan (Stakeholder Engagement)}

Pemangku kepentingan (stakeholder) adalah seluruh pihak yang terkait dengan isu dan permasalahan yang menjadi fokus kajian atau perhatian. Pemangku kepentingan adalah setiap pihak yang berkontribusi serta terkena dampak dari berbagai aktivitas organisasi. Pemangku kepentingan dapat dibedakan ke dalam kelompok primer (yang berpartisipasi aktif) dalam operasi organisasi dan kelompok sekunder yaitu pihak yang berpengaruh secara tidak langsung atau bahkan dipengaruhi oleh organisasi (Susanto, 2014). Dalam konteks Program Revaluasi BMN, pemangku kepentingan diidentifikasikan kepada seluruh pelaksana program yaitu Kementerian Keuangan selaku pengelola BMN dan Kementerian/Lembaga yang menjadi pengguna BMN, termasuk jajaran satuan kerjanya di seluruh Indonesia.

Keterlibatan pemangku kepentingan adalah proses memunculkan berbagai pandangan dari para pemangku kepentingan secara efektif dalam hubungan yang terjadi diantara mereka dengan organisasi, program ataupun proyek (Friedman and Miles 2006). Keterlibatan pemangku kepentingan adalah proses yang digunakan oleh organisasi untuk mengikat para pemangku kepentingan yang relevan dalam rangka mencapai suatu outcome yang diinginkan (AccountAbility, 2008).

Manfaat keterlibatan pemangku kepentingan adalah : (1) menyelesaikan masalah, karena berbagai persoalan organisasi tidak dapat diselesaikan tanpa adanya kolaborasi, pengetahuan dan keahlian pemangku kepentingan; (2) memfasilitasi tumbuhnya kepercayaan (trust) terhadap organisasi; (3) meningkatkan citra organisasi di mata publik.

Tahapan penerapan strategi stakeholder engagement adalah : (1) melakukan pemetaan stakeholder; (2) mengidentifikasi isu-isu penting; (3) menetapkan tujuan; (4) 
menyelesaikan berbagai isu secara berkolaborasi; (5) penanaman keterikatan (embedding engagement) (Smith, 2017).

Prinsip-prinsip dalam stakeholder engagement: (1) mengarah pada tujuan program (purposeful); (2) inklusif (inclusive) bagi seluruh pemangku kepentingan yang relevan; (3) Keterlibatan dilakukan secara terencana dan tepat waktu (timely); (4) transparan; (5) menghormati keahlian, perspektif dan kebutuhan pemangku kepentingan (respectful) (Departement of Health Australian Government, Stakeholder Engagement Framework, 2017).

Alternatif pendekatan yang dapat digunakan dalam stakeholder engagement sebagai berikut:

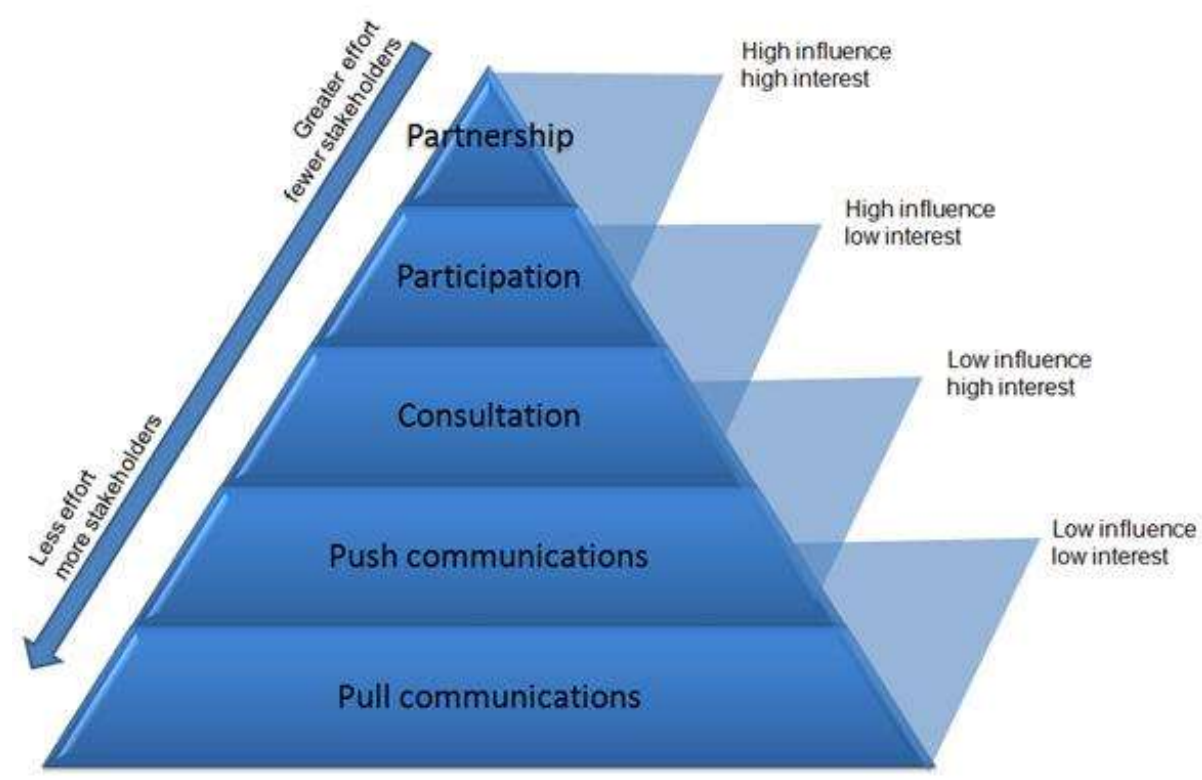

Sumber : https://www.stakeholdermap.com/stakeholder-engagement.html

Berdasarkan gambar tersebut, maka pendekatan keterlibatan pemangku kepentingan dilaksanakan dengan tahapan terlebih dahulu melakukan pemilihan stakeholder berdasarkan pengaruh (influence) dan kepentingannya (interest), selanjutnya pendekatan yang berbeda berdasarkan tipologi stakeholder yang berbeda. Adapun jenis pendekatan yang digunakan dapat dijelaskan sebagai berikut:

\begin{tabular}{|l|l|}
\hline Pendekatan & \multicolumn{1}{c|}{ Penjelasan } \\
\hline Partnership & $\begin{array}{l}\text { Membagi peran dan tanggung jawab (shared accountibility and } \\
\text { responsibility). Keterikatan (engagement) bersifat dua arah dan } \\
\text { terjadi pembelajaran bersama, pengambilan keputusan dan } \\
\text { aksi bersama. }\end{array}$ \\
\hline Participation & $\begin{array}{l}\text { Bagian dari tim. Dilibatkan dalam penyelesaian tugas } \\
\text { tertentu atau tanggung jawab untuk area/aktivitas tertentu } \\
\text { saja. Keterikatan (engagement) dua arah dengan tanggung } \\
\text { jawab yang terbatas. }\end{array}$ \\
\hline Consultation & $\begin{array}{l}\text { Dilibatkan, tapi tidak diberikan tanggung jawab serta tidak } \\
\text { dapat mempengaruhi hal-hal di luar area yang }\end{array}$ \\
\hline
\end{tabular}




\begin{tabular}{|c|l|}
\hline $\begin{array}{c}\text { Push } \\
\text { Communications }\end{array}$ & $\begin{array}{l}\text { dikonsultasikan. Keterikatan dua arah yang terbatas. } \\
\text { Organisasi mengajukan permintaan, stakeholder merespon. }\end{array}$ \\
\hline $\begin{array}{l}\text { Keterikatan satu arah. Organisasi menyebarkan informasi } \\
\text { kepada semua kelompok stakeholder dengan menggunakan } \\
\text { berbagai saluran seperti email, surat, webcasts, podcasts, } \\
\text { video, ataupun leaflet. }\end{array}$ \\
\hline communications & $\begin{array}{l}\text { Keterikatan satu arah. Informasi telah disediakan dan } \\
\text { stakeholder menentukan pilihannya misalnya webpages atau } \\
\text { billboard. }\end{array}$ \\
\hline
\end{tabular}

Selain itu, untuk mendapatkan gambaran yang lebih tepat mengenai siapa stakeholder kita, serta bagaimana cara mengelolanya, perlu kiranya kita memahami stakeholder mapping matrix di bawah ini:

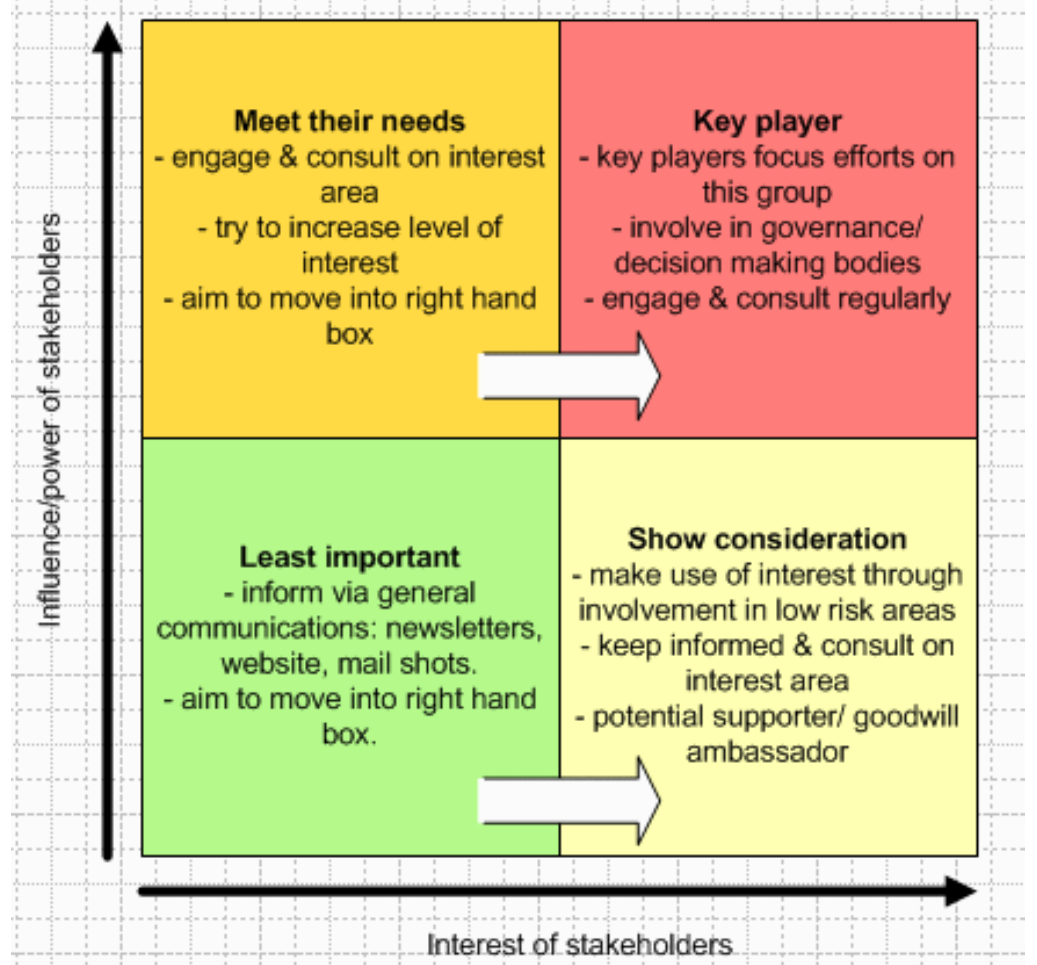

Sumber : https://www.stakeholdermap.com/stakeholder-analysis.html

\section{B. METODE PENELITIAN}

Metode penelitian yang digunakan adalah penelitian kualitatif, dengan melakukan riset kepustakaan dan studi literatur berdasarkan berbagai referensi, dokumen dan sumber yang terpercaya pada Ditjen Kekayaan Negara Kementerian Keuangan.

\section{Informan Penelitian}

Informan penelitian terutama adalah Tim Monitoring dan Evaluasi Revaluasi BMN DJKN serta kantor-kantor daerah yang merupakan instansi vertical DJKN dan satuan kerja Kementerian/Lembaga.

\section{Sumber Data}


Data bersumber pada hasil monitoring dan evaluasi pelaksanaan Revaluasi BMN Tahun 2017 yang dilaksanakan oleh Tim Monitoring dan Evaluasi Revaluasi BMN DJKN sebagai data primer.

Sedangkan data sekunder diperoleh dari berbagai sumber yang berhubungan dan atau menunjang penelitian.

\section{Teknik Pengumpulan Data}

Teknik pengumpulan data yang dilakukan adalah dengan melakukan pengamatan terhadap berbagai dokumen untuk mendapatkan data dan informasi yang relevan diantaranya hal yang berkaitan dengan laporan Tim Pelaksana Revaluasi BMN Kementerian Keuangan, serta beberapa laporan yang diperoleh dari Tim Monitoring Pelaksanaan Revaluasi BMN Ditjen Kekayaan Negara.

\section{Rancangan Analisis Data}

Rancangan analisis data dalam penelitian ini meliputi:

a. Reduksi data

b. Penyajian data

c. Penarikan kesimpulan/verifikasi

\section{HASIL PENELITIAN DAN PEMBAHASAN}

\section{Pelaksanaan Revaluasi Barang Milik Negara}

Kegiatan revaluasi BMN dilaksanakan berdasarkan Peraturan Presiden Nomor 75 Tahun 2017 tentang Penilaian Kembali Barang Milik Negara/Daerah yang merupakan aturan pelaksanaan dari Peraturan Pemerintah Nomor 27 Tahun 2014 tentang Pengelolaan Barang Milik Negara/Daerah. Di dalam Perpres Nomor 75 Tahun 2017 tersebut dinyatakan bahwa Penilaian Kembali adalah proses revaluasi sesuai Standar Akuntansi Pemerintahan yang metode penilaiannya dilaksanakan sesuai Standar Penilaian. Peraturan lainnya yang menjadi pelaksanaan kebijakan tersebut adalah Peraturan Menteri Keuangan (PMK) Nomor 118/PMK.06/2017 tentang Pedoman Pelaksanaan Penilaian Kembali BMN, dan PMK Nomor 111/PMK.06/ 2017 tentang Penilaian BMN.

Adapun yang dimaksud dengan Barang Milik Negara adalah semua barang yang dibeli atau diperoleh atas beban Anggaran Pendapatan dan Belanja Negara atau berasal dari perolehan lainnya yang sah. Sedangkan Barang Milik Daerah (BMD) adalah semua barang yang dibeli atau diperoleh atas beban Anggaran Pendapatan dan Belanja Daerah atau berasal dari perolehan lainnya yang sah.

BMN yang dilakukan penilaian adalah untuk aset yang tergolong sebagai aset tetap, yaitu aset berwujud yang mempunyai masa manfaat lebih dari 12 (dua belas) bulan untuk digunakan, atau dimaksudkan untuk digunakan dalam kegiatan pemerintah atau dimanfaatkan oleh masyarakat umum. Aset tetap yang menjadi target revaluasi BMN adalah tanah, gedung dan bangunan, jalan, irigasi dan jaringan.

Program revaluasi BMN paling sedikit meliputi kegiatan : (1) penyediaan data awal; (2) inventarisasi; (3) penilaian; (4) tindak lanjut hasil inventarisasi dan penilaian; (5) monitoring dan evaluasi. Program revaluasi BMN dilaksanakan pada tahun 2017 dan tahun 2018.

Pelaksanaan revaluasi BMN dikoordinasikan oleh Menteri Keuangan selaku Pengelola Barang Milik Negara, yang merupakan bagian dari kewenangan Menteri Keuangan selaku Bendahara Umum Negara berdasarkan Undang-undang Nomor 1 
Tahun 2004 tentang Perbendaharaan Negara. Sedangkan untuk BMD dilaksanakan oleh masing-masing pimpinan daerah yang dikoordinasikan oleh Menteri Dalam Negeri.

Hasil revaluasi BMN tahun 2017 dan 2018 yang dilakukan terhadap 945.460 item BMN tersebut, mengakibatkan kenaikan nilai BMN dari semula Rp1.538,18 triliun menjadi Rp5.728,49 triliun atau naik sebesar Rp4.190,31 triliun (272\%). Terhadap hasil revaluasi BMN tersebut, Badan Pemeriksa Keuangan (BPK) belum bisa menerima hasil penilaian kembali BMN yang dilakukan pemerintah pada tahun 2017 dan 2018 serta meminta pemerintah untuk (1) mereviu dan memperbaiki kembali data/hasil inventarisasi, serta data hasil penilaian pada aplikasi SIMAN; dan (2) melakukan penilaian kembali sesuai petunjuk teknis penilaian dengan memperhatikan ketentuan yang berlaku. Selain itu, BPK juga memberikan beberapa catatan terkait keberadaan aset, status kepemilikan, peruntukan aset yang belum jelas, serta mispersepsi terhadap metode yang digunakan dalam melakukan revaluasi BMN (Kemenkeu, 2019).

\section{Kendala Pelaksanaan Revaluasi BMN}

Memperhatikan hasil monitoring yang dilaksanakan oleh Tim Monitoring dan Evaluasi Penilaian Kembali BMN Direktorat Jenderal Kekayaan Negara (DJKN), dalam kaitannya dengan keterlibatan pemangku kepentingan diperoleh beberapa catatan sebagai berikut:

1. Rendahnya kemampuan/pengetahuan SDM satuan kerja mitra DJKN di daerah mengenai Program Revaluasi BMN. Yang dimaksud dengan rendahnya pengetahuan tersebut adalah ketidakpahaman SDM pada satuan kerja kementerian/lembaga mengenai esensi program Revaluasi BMN, proses, dan tujuannya. Termasuk dalam aspek ini adalah mengenai banyaknya SDM satuan kerja yang tidak bisa mengisi format inventarisasi BMN dengan baik, serta keengganan melakukan koreksi ataupun tidak memahami proses koreksi.

2. Rendahnya komitmen satuan kerja Kementerian/Lembaga terhadap kesuksesan Program Revaluasi BMN. Komitmen dalam hal ini adalah masalah keterlibatan, antusiasme dan loyalitas yang ditunjukkan oleh satuan kerja mitra DJKN Kementerian Keuangan, terhadap kesuksesan program Revaluasi BMN. Termasuk dalam aspek ini adalah pada saat proses revaluasi di akhir tahun 2017, masih banyak satuan kerja yang belum mau menyerahkan form pendataan, lemahnya koordinasi internal antara kantor pusat Kementerian/Lembaga dengan kantor daerahnya, tidak menyediakan SDM yang mendampingi Tim Pelaksana Revaluasi BMN Kementerian Keuangan, masih banyak yang belum mau melaksanakan inventarisasi BMN, serta dijumpainya satuan kerja Kementerian/Lembaga yang tidak mengijinkan Tim Pelaksana Revaluasi BMN Kemenkeu untuk mendatangi lokasi aset/BMN yang harus dilakukan revaluasi.

3. Lemahnya pengelolaan BMN oleh satuan kerja pada Kementerian/Lembaga, yang ditunjukkan oleh beberapa hal seperti tidak dapat menunjukkan lokasi ataupun fisik $\mathrm{BMN}$, tidak memahami pengelolaan $\mathrm{BMN}$, tidak mengetahui bahwa aset yang dikelolanya adalah BMN, ketidaksesuaian antara pencatatan aset BMN dan fakta di lapangan, serta tidak ditemukan adanya dokumen pendukung atas pengelolaan BMN. 
Atas hasil monitoring pada tahun 2017 tersebut, Tim Monitoring menyimpulkan bahwa permasalahan yang dihadapi dalam pelaksanaan revaluasi BMN adalah sebagai berikut:

1. Rendahnya kemampuan/pengetahuan SDM satuan kerja mitra DJKN di daerah mengenai Program Revaluasi BMN (menyumbang sebesar 44\%), lemahnya pengelolaan BMN oleh satuan kerja Kementerian/Lembaga (40\%), serta Rendahnya komitmen satuan kerja kementerian/Lembaga terhadap kesuksesan revaluasi $(16 \%)$.

2. Masalah komitmen satuan kerja bukanlah masalah yang mendasar, dalam artian bahwa tidak ada satuan kerja yang tidak mau bekerja sama dengan Kemenkeu dan kantor daerahnya. Keengganan bekerja sama lebih disebabkan mereka belum memahami program revaluasi, atau bahkan yang lebih fundamental memang persoalan pengelolaan BMN dianggap sebagai bukan hal yang penting bagi satuan kerja kementerian/lembaga.

Masalah lemahnya koordinasi antar Lembaga Pemerintah banyak diungkap oleh para peneliti. Koordinasi yang lemah dalam pengelolaan KPH pengelolaan hutan dengan para stakeholder, terutama antara KPH dengan instansi pusat, dan juga dengan instansi daerah, lembaga ilmiah, perguruan tinggi dan lembaga adat (Sylviani dan Yosefi, 2015). Lemahnya koordinasi juga mengakibatkan layanan publik berupa BPJS menjadi tidak efektif (Amir dkk, 2018). Koordinasi menjadi lemah dapat disebabkan oleh faktor tidak diterapkannya insentif koordinasi dan kalender pertemuan rutin serta tidak adanya hubungan hirarkis antar institusi pengelola, perbedaan spesialisasi kerja dan orientasi kerja yang mengakibatkan lemahnya hubungan koordinatif antar institusi pengelola (Prabandary, 2016).

Koordinasi dapat berjalan dengan baik dan efektif terhadap tujuan organisasi jika didukung dengan adanya kesepakatan, adanya dana, adanya sarana dan prasarana, dan partisipasi dari peserta (Debrilianawati dkk, 2011). Koordinasi dan pengawasan berpengaruh positif terhadap efektivitas organisasi. Koordinasi harus dimulai dari tahap permulaan dan perbedaan pandangan harus dikemukakan secara terbuka (Nazarudin, 2016). Koordinasi yang mampu memenuhi high performance work practice disebabkan oleh adanya staf yang berkualitas (kriteria seleksi staf), reward bagi petugas, akses penyelesaian masalah antar unit kerja dan adanya koordinasi antar unit kerja yang bersifat rutin/berkala (Sari dan Wulandari, 2015).

\section{Analisis Atas Pelaksanaan Revaluasi BMN}

Berdasarkan hasil pelaksanaan revaluasi BMN tersebut ditemukan hal penting yaitu keengganan satuan kerja Kementerian/Lembaga untuk bekerja sama mensukseskan program revaluasi karena adanya anggapan bahwa persoalan pengelolaan BMN bukanlah persoalan yang penting bagi mereka. Padahal program tersebut telah memiliki landasan hukum yang kuat baik Undang-undang, Peraturan Pemerintah maupun Peraturan Presiden.

Dalam pelaksanaan revaluasi BMN, hal-hal terkait stakeholder engagement yang dilakukan oleh Ditjen Kekayaan Negara Kemenkeu secara kronologis di sepanjang tahun 2017 antara lain: 


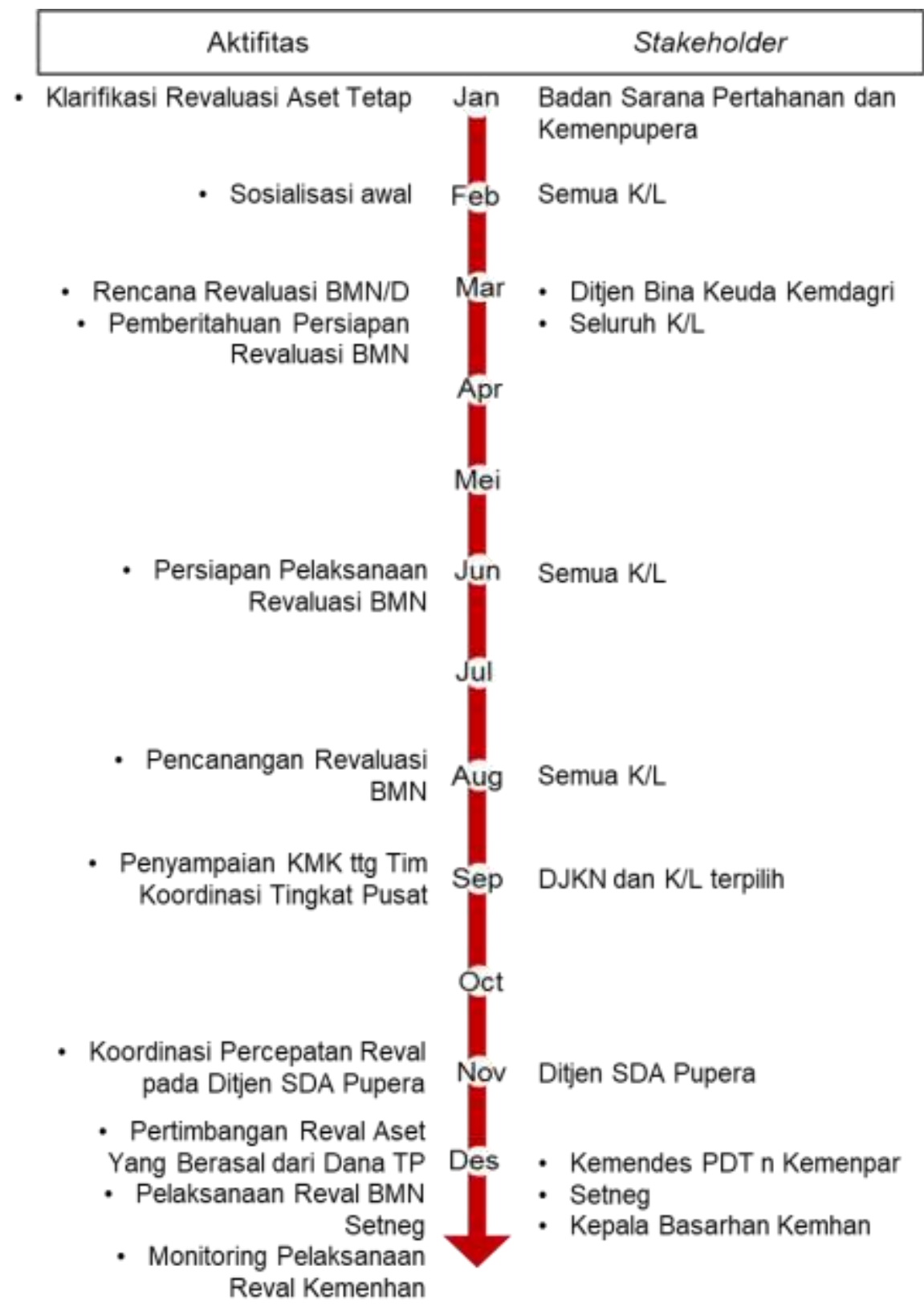

Berdasarkan kronologi tersebut, maka kegiatan pengelolaan stakeholder dapat dikelompokkan sebagai berikut:

a. Partisipasi : dalam bentuk melibatkan Kementerian/Lembaga tertentu di dalam team work dengan kendali sebagian besar berada pada DJKN;

b. Konsultansi : yang banyak dilakukan oleh DJKN dengan beberapa Kementerian/Lembaga yang dinilai penting dan strategis yaitu Kemenpupera, Kemenhan, Kepolisian RI, dan Kemenristekdikti. Termasuk dalam kegiatan konsultatif adalah sosialisasi, grup whatsapp yang dilakukan dengan cara berdiskusi/konsultasi sedangkan peran dan tanggung jawab tetap pada DJKN;

c. Push Communication : kegiatan ini banyak dilakukan DJKN melalui surat, email, website, video dan leaflet.

Dari data tersebut di atas juga terlihat bahwa kegiatan yang berupa partnership belum dilakukan oleh DJKN, kegiatan pengelolaan stakeholder yang masuk dalam kelompok partnership ditandai dengan terjadinya pembelajaran bersama, keputusan bersama dan aksi bersama. Dalam hal ini posisi stakeholder dipersepsikan termasuk kelompok high interest and high influence. 
Hal lain yang dapat ditangkap dari informasi tersebut adalah persepsi DJKN terhadap stakeholder-nya dalam program Revaluasi BMN belum ada yang termasuk dalam pola high influence and high interest. Tetapi masih dalam kelompok high influence and low interest, low influence and high interest, atau low influence and low interest.

Jika diperhatikan dari aktifitas pengelolaan stakeholder tersebut di atas, maka kita memperoleh gambaran bahwa beberapa stakeholder yang sering menjadi sasaran untuk mendapat perhatian "lebih" adalah Kementerian Pertahanan dan Kementerian Pupera. Hal tersebut dilihat dari dokumen yang disampaikan dan juga aktifikas komunikasi dengan dua kementerian tersebut dilakukan sangat intensif. Dapat dipahami bahwa dua kementerian tersebut lebih mendapat perhatian mengingat jumlah item BMN yang menjadi target Revaluasi BMN pada dua kementerian tersebut adalah yang terbesar dari seluruh Kementerian/Lembaga. Jumlah item BMN untuk Kemenhan dan Kemenpupera adalah sekitar 51\% dari total target nomor urut pendaftaran (NUP) Revaluasi BMN Tahun 2017 dan 2018.

Jika Kementerian/Lembaga dikelompokkan berdasarkan jumlah NUP BMN yang menjadi target revaluasi, maka yang termasuk dalam kelompok 15 besar adalah sebagai berikut:

\begin{tabular}{|c|c|c|}
\hline No & Kementerian/Lembaga & Jumlah NUP (Targot) \\
\hline 1 & Kementerian Pekerjaan Umum dan Perumahan Rakyat & 344.993 \\
\hline 2 & Kementerian Pertahanan & 130.151 \\
\hline 3 & Kepolisian Republik Indonesia & 61.165 \\
\hline 4 & Kementerian Agama & 55.397 \\
\hline 5 & Kementerian Perhubungan & 52.869 \\
\hline 6 & Kementerian Pertanian & 39.079 \\
\hline 7 & Kementerian Riset, Teknoiogi dan Pendidikan Tinggi & 21.850 \\
\hline 8 & Kementerian Keuangan & 18.877 \\
\hline 9 & Kementerian Hukum dan HAM & 17.092 \\
\hline 10 & Mahkamah Agung & 11.029 \\
\hline 11 & Kementerian Kelautan dan Perikanan & 9.769 \\
\hline 12 & Kementerian Lingkungan Hidup dan Kehutanan & 9.717 \\
\hline 13 & Kementerian Kesehatan & 8.644 \\
\hline 14 & Kejaksaan Agung & 7.652 \\
\hline 15 & $\begin{array}{l}\text { Kementerian Desa, Pembangunan Daerah Tertinggal dan } \\
\text { Transmigrasi }\end{array}$ & 5.429 \\
\hline
\end{tabular}

Sumber: Kementerian Keuangan, diolah.

Jumlah total NUP untuk 15 kementerian/lembaga tersebut adalah 793.712 atau sekitar 85\% dari total target NUP untuk program Revaluasi BMN Tahun 2017 dan 2018.

Atas dasar analisis kegiatan revaluasi BMN di atas, maka dapat dilihat bahwa aktifitas yang bersifat partnership yang ditunjukkan oleh adanya pembelajaran bersama, keputusan bersama dan aksi bersama belum menjadi pilihan dalam pengelolaan stakeholder Program Revaluasi BMN. Di sisi lain, pada berbagai tahapan 
revaluasi BMN dibutuhkan keterlibatan stakeholder untuk mensukseskan program, dengan gambaran sebagai berikut:

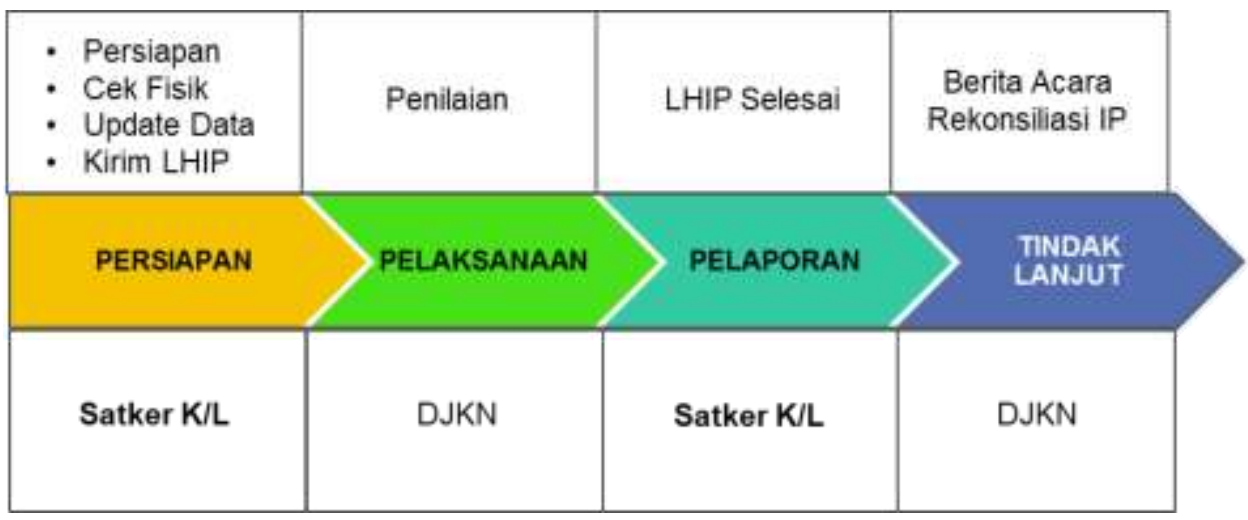

Dari gambar tersebut di atas, maka DJKN bersama-sama dengan satker menuntaskan seluruh tahapan proses. Tidak mungkin tercapai hasil yang baik pada akhirnya jika tahapan-tahapan yang melibatkan satuan kerja/Kementerian/Lembaga tidak terlaksana dengan baik.

Namun demikian, berdasarkan analisis permasalahan sebagaimana diungkapkan sebelumnya, ternyata stakeholder masih memiliki kendala mengenai pengetahuan/kemampuan SDM tentang Revaluasi BMN, bahkan tidak menganggap kegiatan penatausahaan BMN sebagai tugas yang penting. Akibatnya banyak peran yang seharusnya dilakukan oleh stakeholder diambil alih oleh DJKN dengan pertimbangan kecepatan waktu penyelesaian program revaluasi BMN Tahun 2017. Hal ini yang perlu diupayakan solusinya sehingga pemahaman satker terhadap Program Revaluasi BMN meningkat, sekaligus dapat meningkatkan keterikatan satker dalam pelaksanaannya.

Apabila dilihat dari aspek efektivitas, maka implementasi kebijakan berupa Program Revaluasi BMN belum mencapai kriteria efektivitas. Hal ini ditunjukkan oleh beberapa hal yaitu belum diterimanya laporan hasil penilaian Revaluasi BMN oleh BPK, yang dengan demikian, hingga tahun 2019, nilai wajar dari aset negara berupa BMN belum dapat disajikan oleh pemerintah. Jika efektivitas ditinjau dari aspek yang menyeluruh (integratif), maka pelaksanaan Revaluasi BMN masih terkendala dari aspek lemahnya koordinasi/kolaborasi dan keterlibatan pemangku kepentingan.

\section{Alternatif Solusi}

Memperhatikan permasalahan sebagaimana tersebut di atas, tahap pertama bagi DJKN adalah melakukan stakeholder mapping berdasarkan tingkat pengaruh (influence) dan kepentingan (interest) dari para stakeholder DJKN terhadap program revaluasi BMN. Mengukur pengaruh (influence) stakeholder dapat dilakukan dengan melihat seberapa besar kemampuannya untuk mempengaruhi kualitas outcome, ketepatan waktu penyelesaian, serta keberhasilan atau kegagalan program Revaluasi BMN. Sedangkan memahami seberapa besar interest dari stakeholder antara lain dapat dilakukan dengan mengukur keinginan untuk mendapatkan manfaat dari program Revaluasi BMN.

Setelah mempertimbangkan dua hal tersebut, selanjutnya stakeholder dimasukkan ke dalam matrik di bawah ini. Jika berdasarkan jumlah NUP saja yang dipertimbangkan, maka kelompok stakeholder dikategorikan sebagai berikut: 


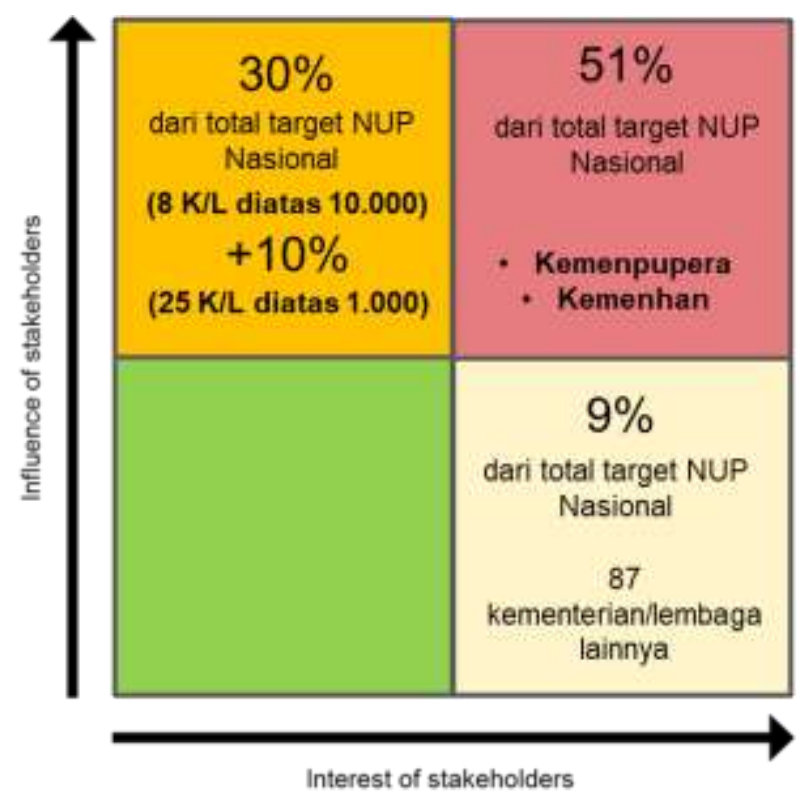

Memasukkan dua kementerian yaitu Kemenpupera dan Kemenhan ke dalam kelompok key player sangat wajar bukan semata-mata karena $51 \%$ target nasional berada pada kementerian ini, namun dua kementerian ini pasti memiliki kepentingan yang besar terhadap keberhasilan Revaluasi BMN, yang akan membawa pengaruh pada akuntabilitas pengelolaan BMN di kementerian tersebut. Pada kenyataannya mereka belum memahami manfaat dari program ini, oleh karenanya proses edukasi untuk pembentukan komitmen perlu lebih gencar dilakukan. Namun demikian, untuk mendapatkan hasil yang terbaik dalam melakukan identifikasi stakeholder ini, perlu kiranya dilakukan upaya edukasi antara lain dengan memperbanyak focus group discussion, formal and informal meeting.

One size does not fit all. Perlu dipertimbangkan bahwa setiap kelompok stakeholder memiliki karakteristik yang berbeda dengan yang lainnya, oleh karena itu sangat diperlukan stakeholder mapping guna menentukan pendekatan yang berbeda bagi kelompok yang berbeda.

Atas dasar stakeholder mapping tersebut, maka langkah selanjutnya adalah pendekatan yang dilakukan terhadap masing-masing kelompok stakeholder tersebut seharusnya berbeda-beda. Untuk Kemenpupera dan Kemenhan, yang dikelompokkan sebagai key player dengan berbagai pertimbangan yang disepakati, maka pendepatan partisipatif semata tidak mencukupi efektifitas engagement-nya. Key player perlu dilibatkan dalam menyusun rencana aksi, terlibat dalam merancang strategi, serta melakukan aksi bersama DJKN antara lain dalam bentuk sosialisasi, monitoring dan evaluasi bersama. Termasuk hal penting bagi key player tidak ada salahnya mendapatkan alokasi anggaran yang memadai, agar involvement nya di dalam setiap tahapan program Revaluasi BMN dapat terjaga dengan baik.

Sementara itu untuk kelompok yang masuk dalam kelompok meet their need atau high influence and low interest, pendekatannya seperti yang telah dilakukan selama ini melalui keanggotaan Tim, dan konsultansi pada hal-hal tertentu yang menjadi perhatian.

Sedangkan kelompok stakeholder yang masuk dalam kelompok show consideration pendekatan yang dilakukan adalah dengan memberikan ruang konsultansi, menyediakan berbagai informasi yang mereka butuhkan melalui website, sosialisasi, leaflet, email atau surat menyurat. 
Berikut ini gambar yang menunjukkan pilihan pendekatan kepada stakeholder berdasarkan hasil mapping.

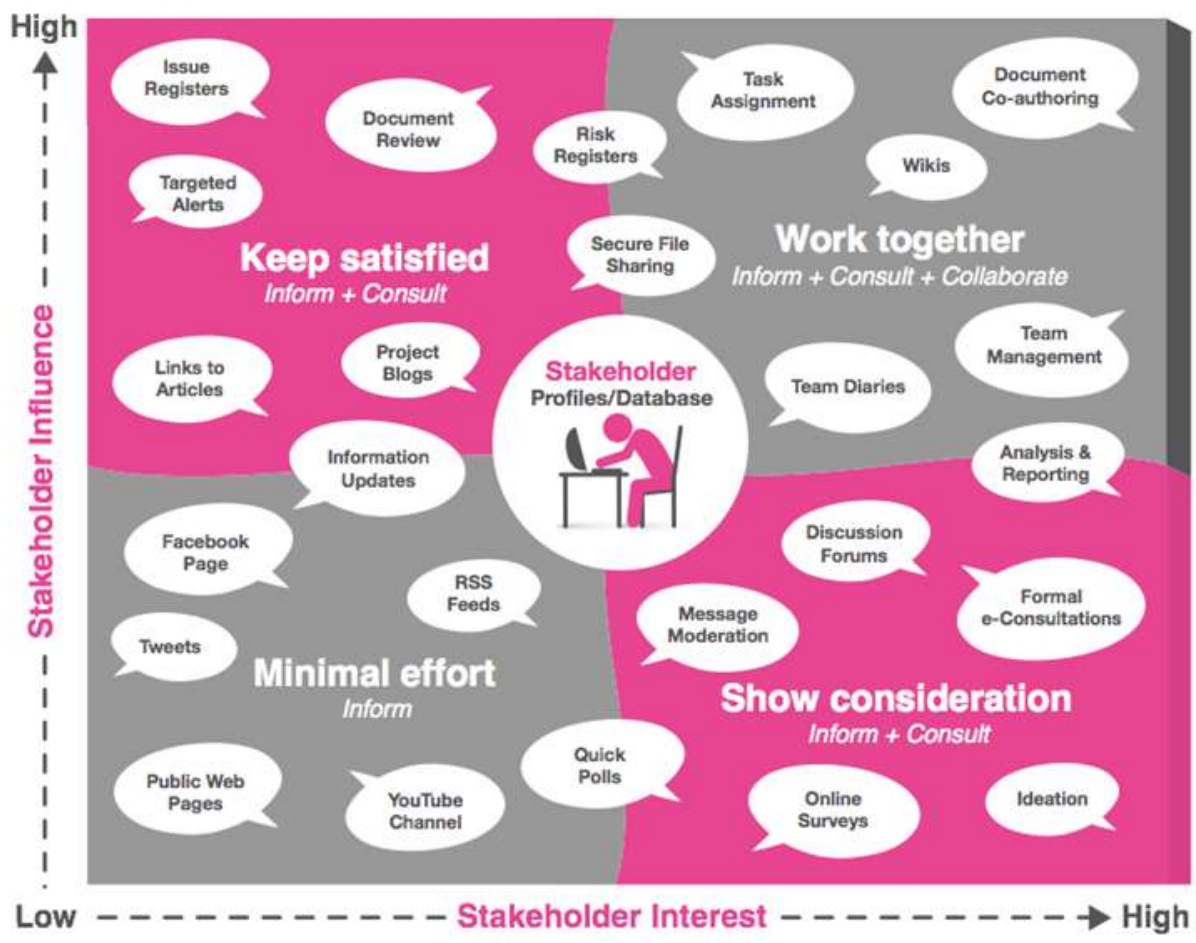

Sumber : http://cloud-collaboration.kahootz.com/how-to-create-an-effectivestakeholder-engagement-strategy

\section{Pembelajaran Yang Diperoleh}

Memperhatikan hasil analisis permasalahan tersebut di atas, bahwa salah satu fenomena yang dapat diambil sebagai pelajaran dari Program Revaluasi BMN adalah lemahnya penatausahaan dan pengelolaan BMN oleh Kementerian/Lembaga. Adalah penting untuk melakukan stakeholder mapping agar dalam jangka panjang bukan hanya knowledge Kementerian/Lembaga mengenai BMN yang semakin meningkat, namun juga komitmen Kementerian/Lembaga mengenai pentingnya pengelolaan BMN menjadi lebih meningkat.

Efektivitas implementasi kebijakan publik bukanlah persoalan bagaimana sebuah kebijakan ditetapkan dan berjalan sesuai keinginan pembuat kebijakan, tetapi perlu memikirkan dampak yang terjadi bagi target kebijakan. Berkaca dari Program Revaluasi BMN, kebijakan telah dirancang dengan baik, namun demikian banyak Kementerian/Lembaga yang tidak paham dan tidak "bergerak" untuk menuju tujuan program. Hal tersebut, lebih karena proses kolaborasi belum berjalan dengan baik dan diperlukan aksi bersama pada tahap persiapan bukan hanya pada tahap pelaksanaan dan evaluasi.

Banyak hal yang perlu dilakukan oleh Kemenkeu agar terjadi komitmen mengenai pentingnya meningkatkan kualitas penatausahaan dan pengelolaan BMN pada Kementerian/Lembaga. Beberapa langkah yang sederhana namun terbukti membawa pengaruh terhadap meningkatnya kolaborasi dan koordinasi adalah sebagai berikut: 


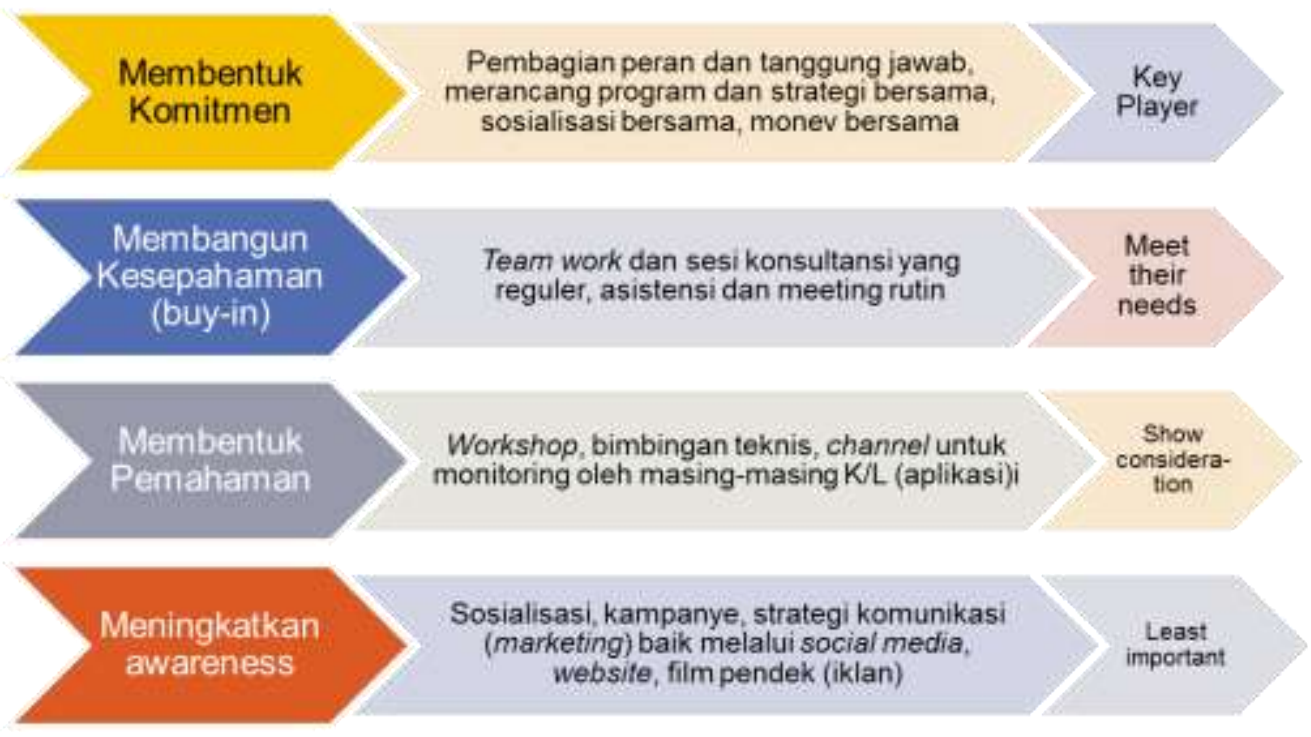

Agar program tersebut dapat terlaksana dengan baik terdapat beberapa prasyarat yang diperlukan antara lain:

1. Memperkuat pemahaman tentang program dan teknis pelaksanaannya secara internal baik di lingkup Kantor Pusat, Kantor Wilayah maupun Kantor Daerah (product knowledge);

2. Dukungan yang kuat dari pimpinan Kementerian Keuangan menjadi daya dorong yang sangat efektif melalui kampanye dan sosialisasi;

3. Dukungan kebijakan keuangan yang lebih fleksibel namun tetap akuntabel sangat penting, mengingat kegiatan ini bersifat nasional dan mengerahkan sumber daya yang luar biasa. Hal ini bukan hanya penganggaran untuk internal Kemenkeu namun membutuhkan kreatifitas dan inovasi agar kebutuhan anggaran kementerian/lembaga yang merupakan key player pun mendapat dukungan.

4. Setiap inisiatif stakeholder engagement wajib dikaitkan dengan visi besar untuk meningkatkan kualitas penatausahaan dan pengelolaan barang milik negara yang tersebar di seluruh kementerian/lembaga, sehingga Revaluasi BMN hanyalah salah satu bagian saja dari keseluruhan proses penatausahaan dan pengelolaan kekayaan negara.

Pembelajaran dari Revaluasi BMN yang telah dilaksanakan oleh Pemerintah Pusat ini perlu menjadi catatan penting bagi Pemerintah Daerah yang hingga saat ini belum melaksanakan penilaian kembali (revaluasi) terhadap barang milik daerah (BMD) yang berada dalam pengelolaan masing-masing daerah. Tentu hal ini akan lebih beraneka ragam implementasinya, karena kondisi daerah yang sangat beragam. Namun demikian, hal-hal baik yang ada pada kegiatan Revaluasi BMN dapat diduplikasi, sedangkan hal-hal yang masih menyisakan catatan kiranya perlu menjadi perhatian semua unsur yang terlibat dalam Revaluasi BMD.

\section{KESIMPULAN}

Penelitian ini menunjukkan beberapa catatan kesimpulan yaitu: implementasi Kebijakan berupa Revaluasi BMN belum memenuhi aspek efektivitas; (2) faktor yang signifikan berpengaruh terhadap keterikatan pemangku kepentingan (stakeholder engagement) dalam program Revaluasi BMN Tahun 2017 adalah rendahnya pengetahuan SDM satker tentang program Revaluasi BMN dan lemahnya 
penatausahaan/pengelolaan BMN pada satker; (3) kegiatan stakeholder engagement yang dilakukan Kemenkeu meliputi partisipasi, konsultansi, push communication dan pull communication. Hal tersebut mengindikasikan bahwa Kemenkeu mengidentifikasi belum ada stakeholder yang memiliki high influence dan high interest terhadap program Revaluasi BMN, karena belum terdapat kegiatan yang bersifat partnership.

Selanjutnya kami merekomendasikan upaya untuk meningkatkan stakeholder engagement dapat dilakukan melalui hal-hal sebagai berikut:

1. Melakukan stakeholder mapping untuk mengidentifikasi pengaruh dan kepentingan para stakeholder;

2. Memilih pendekatan yang tepat untuk setiap kelompok stakeholder dalam rangka mencapai tujuan program dengan efektif;

3. Diperlukan prasyarat untuk kesuksesan program tersebut antara lain:

a. Memperkuat pemahaman tentang program dan teknis pelaksanaannya secara internal baik di lingkup Kantor Pusat, Kantor Wilayah maupun Kantor Daerah (product knowledge);

b. Dukungan yang kuat dari pimpinan Kementerian Keuangan menjadi daya dorong yang sangat efektif melalui kampanye dan sosialisasi

c. Dukungan kebijakan keuangan yang lebih fleksibel namun tetap akuntabel sangat penting, mengingat kegiatan ini bersifat nasional dan mengerahkan sumber daya yang luar biasa. Hal ini bukan hanya penganggaran untuk internal Kemenkeu namun membutuhkan kreatifitas dan inovasi agar kebutuhan anggaran kementerian/lembaga yang merupakan key player pun mendapat dukungan.

d. Setiap inisiatif stakeholder engagement wajib dikaitkan dengan visi besar untuk meningkatkan kualitas penatausahaan dan pengelolaan barang milik negara yang tersebar di seluruh kementerian/lembaga, sehingga Revaluasi BMN hanyalah salah satu bagian saja dari keseluruhan proses penatausahaan dan pengelolaan kekayaan negara.

\section{DAFTAR PUSTAKA}

Amir, M., Aruan, Nakkok., dan Rifki, M.S., (2018), Layanan Badan Penyelenggara Jaminan Sosial (BPJS) di Rumah Sakit Milik Pemerintah Provinsi Jawa Timur, Matra Pembaruan: Jurnal Inovasi Kebijakan.

Anderson, James E. (2011), Public Policy Making: An Introduction, Wadsworth Cengage Learning, Boston, United State of America.

Bal, Menoka, dkk (2013), Stakeholder Engagement: Achieving Sustainability in the Construction Sector, MDPI Journal.

Bourne, Lynda (2015), Series on Effective Stakeholder Engement: Stakeholder Theory, PM World Journal.

Debrilianawati, Dessy., Saleh, Choirul., Hadi, Minto., (2011), Peran dan Koordinasi Antar Instansi Dalam Pemberdayaan Warga Binaan Pemasyarakatan di Lembaga Pemasyarakatan: Studi tentang Program Kemandirian Pelatihan Kerja Pengelolaan Ikan Air Tawar di Lembaga Pemasyarakatan Kelas II B Kota Pasuruan, Jurnal Administrasi Publik (JAP) Vol 1, Nomor 2 Halaman 174-180.

Department of Health Australian Government (2017), Stakeholder Engagement Framework, Australia.

Lane, Jan-Erik, (1995), The Public Sector: Concepts, Models and Apporaches, Third Edition, SAGE Publication, London. 
Lubis, S.B. Hari, Huseini, Martani, (2009), Pengantar Teori Organisasi: Suatu Pendekatan Makro, Departemen Ilmu Administrasi Fakultas Ilmu Sosial dan Ilmu Politik Universitas Indonesia.

Prabandary, Noviana Wahyu, (2016), Koordinasi Antar Institusi Dalam Pengelolaan Benda Cagar Budaya Candi Borobudur.

Nazarudin, (2016), Pengaruh Koordinasi dan Pengawasan Terhadap Efektivitas Organisasi di Lingkungan Pemerintahan Kabupaten Cianjur, Universitas Pasundan Bandung.

Sari, Intan Permata, dan Wulandari, Ratna Dwi, (2015), Penilaian Koordinasi Antarunit Kerja di Rumah sakit Berdasarkan High Perfomance Work Practices, Jurnal Administrasi Kesehatan Indonesia Volume 3 Nomor 2 Juli-Desember 2015.

Sinclair, Marie-Louise (2017), Developing a Model for Effective Stakeholder Engagement, Sinclair Consulting.

Smith, N. Craig dkk (2011), What's at Stake? Stakeholder Engagement Strategy as the Key to Sustainable Growth, Faculty and Research Working Paper, INSEAD.

Susanto, A.B. (2014), Manajemen Stratejik Komprehensif: Untuk Mahasiswa dan Praktisi, Penerbit Erlangga, Jakarta.

Sylviani, Sylviani dan Yosefi, Elvida, (2015), Peran dan Koordinasi Para Pihak Dalam Pengelolaan KPH, e-Journal Penelitian Sosial dan Ekonomi Kehutanan, Kementerian Lingkungan Hidup dan Kehutanan.

Theodoulou, Stella Z., Kofinis, Chris, (2004), The Art of the Game: Understanding American Public Policy Making, Wadsworth/Thomson Learning, Belmont, USA.

Undang-undang Nomor 1 Tahun 2004 tentang Perbendaharaan Negara.

Peraturan Pemerintah Nomor 27 Tahun 2014 tentang Pengelolaan Barang Milik Negara/Daerah.

Peraturan Presiden Republik Indonesia Nomor 75 Tahun 2017 tentang Penilaian

Kembali Barang Milik Negara/Daerah.

Laporan Hasil Monitoring Penilaian Kembali Barang Milik Negara Ditjen Kekayaan

Negara Tahun 2017.

www.kemenkeu.go.id

www.djkn.kemenkeu.go.id 